\title{
Usos do território, modernização e ações políticas conservadoras em Barcarena-PA
}

João Santos Nahum*

\section{Resumo}

Neste artigo enfocamos os usos do território resultantes do projeto de modernização de Barcarena-PA a partir da década de 1980. O corolário desta modernização é o território usado como recurso pelos empreendedores e pela elite governante municipal. Para o restante da população o território é usado como abrigo.

Palavras-chave: Território, modernização, conservação, elite.

Uses of territory, modernization and conservative political actions in Barcarena-PA

\begin{abstract}
In this article we focus on the uses of territory resources in the modernization project of Barcarena-PA, begun in the 1980 decade. The project uses these to benefit the enterprisers and the municipal ruling elite and thus reduces the territory resources the rest of the population uses for shelter.

Key words: Territory, modernization, conservation, élite.

\section{Introdução}

Este artigo enfoca os usos do território em Barcarena-PA a partir da implantação do sistema de engenharia produtor de

* Professor do Núcleo Pedagógico Integrado - NPI/UFPA (joaonahum@uol.com.br-joaonahum17@gmail.com).
\end{abstract}

Geosul, Florianópolis, v. 23, n. 45, p 65-84, jan./jun. 2008 
NAHUM, J.S. Usos do território, modernização e ações políticas ...

alumínio primário da Albrás/Alunorte. Ele adapta o capítulo 1 de "O uso do território em Barcarena: modernização e ações políticas conservadoras" . Nela sustentamos a tese que um sistema de ações conservadoras se reproduz a cada processo de modernização do território em Barcarena. As inovações que o território barcarenense conhece, a partir da implantação da Albrás/Alunorte, na configuração territorial ou na administração pública, reproduzemse de acordo com o sistema de ações conservadoras e compõem uma modernização fabulosa feita de simulações e artifícios, mais preocupada em parecer moderna do que em ser moderna, posto que esconde o sistema de ações políticas dos que usam o território como recurso para garantir os interesses e privilégios de um pequeno círculo de agentes sociais.

\section{O moderno reordenamento territorial de Barcarena}

Na década de 1970 o aumento nos preços do petróleo, seguido de sua exploração cartelizada, através da Organização dos Países Exportadores e Produtores de Petróleo - OPEP, impulsionou um reordenamento na divisão do trabalho em nível global. Segundo M. Santos (1999, p. 106) a divisão do trabalho é "um processo pelo qual os recursos disponíveis se distribuem social e geograficamente". Um aspecto dessa distribuição foi a transferência de plantas industriais produtoras de alumínio primário, gerenciadas por empresas e conglomerados de capital japonês para territórios que melhor oferecessem vantagens competitivas.

Dentre as vantagens, "contou a favor" do território paraense a presença de jazidas de bauxita às margens do rio Trombetas, no município de Oriximiná, conhecidas desde 1963. Mas, o valor real desses recursos não "depende de sua existência separada, mas de

\footnotetext{
${ }^{1}$ Tese de doutoramento defendida por nós, sob a orientação da prof ${ }^{a} \mathrm{dr}^{\mathrm{a}}$. Samira Kahil, em maio de 2006, no programa de pós-graduação em geografia, área de concentração Organização do Espaço da Universidade Estadual Paulista, campus de Rio Claro.
} 
NAHUM, J.S. Usos do território, modernização e ações políticas ...

sua qualificação geográfica, isto é, da significação conjunta que todos e cada qual obtêm pelo fato de participar de um lugar." (SANTOS, 1999, p.107). A qualificação geográfica para a utilização produtiva desses recursos minerais foi construída a partir do convite que o governo brasileiro fez ao grupo japonês da Aluminium Resouces Development Co (ARDECO), para colaborar com a Companhia Vale do Rio Doce (CVRD), então empresa estatal, na realização de estudos para a produção de alumina na região Amazônica.

$\mathrm{O}$ uso das riquezas naturais como recurso do território paraense intensificou-se no regime do pós-1964, culminando com "a recriação, pelos militares, da Amazônia como fronteira" (IANNI, 1981, p.141).O Estado assume, então, papel de avalista da internalização dos interesses externos, representados na Amazônia, dentre outros, pelos grandes projetos e empreendimentos mínerometalúrgicos e hidroelétricos. Atuando como empreendedor o Estado direcionou o fundo público para criar condições territoriais favoráveis aos investimentos nacionais e internacionais em projetos vinculados à silvicultura, à pesca, à agropecuária, ao beneficiamento de madeira, mas, sobretudo às grandes obras de infra-estrutura energética e produção mínero-metalúrgica. Assim é que paradoxalmente no Brasil o fundo público "passou a ser o pressuposto do financiamento da acumulação do capital de um lado, e, de outro do financiamento da reprodução da força de trabalho" (OLIVEIRA 1998, p.19-20).

O governo federal ofereceu aos empreendedores da Albrás/Alunorte uma série de incentivos visando atrair para a região a planta industrial de alumínio. A energia foi um dos principais atrativos, não só pela quantidade, que a produção de alumínio demanda, como pelo preço e pela forma como este insumo foi ofertado. Em setembro de 1973 a ELETRONORTE Centrais Elétricas do Norte do Brasil S/A - foi criada para ampliar a exploração do potencial energético da região e construir um grande sistema de engenharia, a Usina Hidrelétrica de Tucuruí 
NAHUM, J.S. Usos do território, modernização e ações políticas ...

fornecedora de energia aos Grandes Projetos de produção mínerometalúrgicos.

O Estado brasileiro, além da Usina Hidrelétrica de Tucuruí, ainda custeou e construiu todos os sistemas de engenharia de transporte no setor hidroviário e rodoviário, um porto graneleiro e de carga geral para navios de grande calado, além do núcleo urbano de Vila dos Cabanos.

Segundo M. Lobo (1996), o leque de benefícios concedidos pelo Estado aos empreendedores do alumínio é ampliado quando o projeto Albrás/Alunorte, que nasce no âmbito do III Plano de Desenvolvimento da Amazônia -1980-1985, passa, em 1981, a integrar o conjunto dos empreendimentos do Programa Grande Carajás - PGC, recebendo assim tratamento especial pelos órgãos e entidades da Administração Federal.

Todo um sistema de ações governamentais vai financiando e criando as condições infra-estruturais e normativas para viabilizar a ALBRÁS - Alumínio Brasileiro S/A. Tais conjuntos de ações são imposições exógenas e corporativas, portanto, privando o lugar de autonomia política. Desta forma também, "o Estado prepara as condições para que as maiores empresas, sobretudo as estrangeiras, possam apropriar-se da mais-valia social local, que elas mandam para fora ou utilizam para incrementar seus ativos e aumentar, assim, suas possibilidades de ampliar a própria mais-valia" (SANTOS, 2005, pp.45-46).

\section{Ações governamentais e a desestruturação da dinâmica territorial local}

No território de Barcarena, a população residente na área destinada para a construção do complexo industrial sofreu as conseqüências das ações governamentais. Ela foi tratada pelo poder estatal e empresarial como obstáculo ao processo de modernização e sua retirada foi o preço exigido.

No processo de remoção da população a ação estatal usou de todo recurso normativo do Instituto de Terras do Pará - ITERPA, do Instituto de Colonização e Reforma Agrária - INCRA, da 
NAHUM, J.S. Usos do território, modernização e ações políticas ...

Companhia de Desenvolvimento Industrial do Pará- CDI, e da Companhia de Desenvolvimento de Barcarena - CODEBAR.

Segundo Maia e Moura (1995), a fim de que fosse posto em prática o mecanismo jurídico das desapropriações foi designada uma instituição estadual, CDI, que realizou 404 desapropriações no período de 1983 a 1984 numa área de 40.000 ha, e uma federal, CODEBAR, que efetuou 155 desapropriações numa área de 60.104 ha, no período de 1983 a 1984. A área desapropriada pelo CDI destinou-se à implantação do Complexo Industrial e à construção do Porto e a da CODEBAR à implantação do Núcleo de Barcarena. As desapropriações foram conduzidas em diferentes momentos, a ritmos diversos e com critérios variados. Evidentemente que essa aparente desorganização tinha como objetivo dificultar uma possível articulação da população.

Seguindo a perspectiva de "espaço vazio", que predominava nos três primeiros planos de desenvolvimento da Amazônia, o governo do estado do Pará declarou, através do Decreto $n^{\circ} 10.064$ de 25 de abril de 1977, de utilidade pública para fins de desapropriação, imóveis e benfeitorias localizadas em Barcarena, com o objetivo de implantar o Projeto Albrás/Alunorte.

Inicialmente, segundo Maia e Moura (1995), a Companhia de Desenvolvimento Industrial do Pará - CDI - e depois a Companhia de Desenvolvimento de Barcarena - CODEBAR, desconsiderando o sítio familiar como unidade de produção e as relações sociais que lhes são específicas, estipularam para cada uma das famílias desapropriadas pequenos lotes urbanos de 9x30 $\mathrm{mts}$ ou $15 \times 30 \mathrm{mts}$, ou lotes rurais de apenas 5 ha. Desencadeava-se todo um processo de reestruturação agrária e urbana que transformou o colono produtor em assentado consumidor.

O descontentamento das famílias assumiu forma coletiva na Associação dos Desapropriados de Barcarena - ADEBAR, fundada em 1986. A Associação, de acordo com Vasconcelos (1996), foi formada por 494 famílias desapropriadas das áreas de implantação do complexo industrial, com a finalidade de congregar todos os expropriados e repassar as experiências de 
NAHUM, J.S. Usos do território, modernização e ações políticas ...

expropriação para outros moradores que estão ameaçados de novas desapropriações de sítios no município. Mas o objetivo primeiro é reivindicar as perdas monetárias provenientes da subvalorização das propriedades e benfeitorias pelo CDI e pela CODEBAR.

A necessidade de organização e resistência acontece porque a implantação da Albrás/Alunorte fragmentou a unidade produtiva local, os sítios. Estes compreendiam, geralmente, pequenas propriedades em média de 20 ha, com casas construídas pelas e para várias famílias. As casas eram "predominantemente de madeira, algumas de barro, cobertas de palha e/ou telha, a maioria possuía 02 compartimentos com uma área que variava de 30 a $90 \mathrm{~m}^{2}$. O sanitário ficava fora da casa, geralmente a céu aberto." (MAIA e MOURA, 1995, p.234). No terreno os colonos, a maioria de origem cabocla, nascida e criada no lugar, cuidavam de árvores frutíferas, desenvolviam a agricultura rudimentar de macaxeira e mandioca e, em função deste produto, erguiam a casa de farinha e escavavam o poço de água. A exploração tanto dos rios como das matas possuía caráter coletivo e não havia cercado que os delimitasse, pois as redes de solidariedade permitiam aos colonos conhecer onde começava um sítio e terminava o outro. Da mandioca, além do fabrico de farinhas, eles obtinham o tucupi e a tapioca, todos integrando a sua dieta alimentar. Complementando o sustento familiar coletavam frutas, caçavam animais silvestres, pescavam e criavam galinhas e porcos.

Era incomum a utilização de tecnologia moderna; onde havia, resumia-se ao consumo de energia elétrica. Daí a ocupação do trabalho de todos da família - homens, mulheres, idosos, adultos, jovens e crianças - empregavam seus dias na obtenção de produtos para seu sustento. $O$ trabalho adquiria um sentido profundamente socializador, por meio dele os mais novos cresciam e eram educados, no e para o trabalho. Meninas e meninos assimilavam os papéis que desempenhariam quando adultos. A sociabilidade do trabalho organiza mutirões, em que várias famílias associavam-se para executar tarefas como roça, fabrico de carvão, 
NAHUM, J.S. Usos do território, modernização e ações políticas ...

construção de casas, pontes e trapiches, e na limpeza de igarapés. Segundo Pontes (1985 apud MAIA e MOURA, 1995, p. 242) "no processo do mutirão predominava o companheirismo enquanto forma de sociabilidade. Não havia nenhuma forma de pagamento que caracterizasse a venda de força de trabalho". A relação de ajuda mútua garantia ao seu legítimo dono o direito sobre a venda do produto e a certeza de contar com a solidariedade de parentes e amigos quando necessária. O mutirão é também um meio do camponês caboclo, desenvolver outras dimensões da vida social. No lugar onde se realiza o mutirão são reforçadas amizades, relações de compadrio, trocas de informações.

A desterritorialização do colono, a expropriação da sua terra, destruiu a unidade familiar de produção e os laços societais alicerçados começam a romper-se. Os sítios foram eliminados da fração do território onde estão o complexo Albrás/Alunorte e outras empresas que posteriormente chegaram, deixam de ser a unidade produtiva predominante na economia barcarenense. A unidade de produção familiar foi quebrada, política e territorialmente, para que a força de trabalho aí disponível e a migrante fossem utilizadas e empreendessem a edificação dos sistemas de objetos necessários à produção e circulação de alumínio primário.

Neste momento os governos estadual e federal são os agentes decididores, pois escolhem o que "vai ser difundido e, muito mais, a ação que, nesse sentido, se vai realizar" (SANTOS, 1999 , p. 65). O Estado, na condução dos processos de desapropriação, sustentou "a ação da lei” em oposição à legitimidade de usufruto da terra pelos colonos, exigindo deles as escrituras das propriedades. Por isso, nos processos de desapropriação e de indenização, houve subvalorização das unidades familiares, pois aos olhos do poder estatal e empresarial os colonos eram posseiros e não proprietários legais.

De outro lado, o fabuloso discurso do aumento do número de empregos diretos "parecia", durante a implantação do projeto, dinamizar a economia municipal e assim justificar as 
NAHUM, J.S. Usos do território, modernização e ações políticas ...

desapropriações. Enormes contingentes de mão-de-obra, de distintas qualificações, foram recrutados pelas empreiteiras ligadas ao setor da construção civil. Segundo um diretor do departamento de recursos humanos da Albrás, "durante a construção da Albrás chegamos a ter cerca de 5.000 trabalhadores no canteiro de obras e mais uns 1.000 na construção da Vila dos Cabanos. (informação verbal $)^{2}$.

Algumas empresas escolheram o município de Abaetetuba como lugar de recrutamento de mão-de-obra, então, a maior cidade da micro-região do Baixo Tocantins. Centro polarizador regional, dispondo de razoável sistema de serviços de comunicação, comércio e transporte, além de escritórios da Secretaria Estadual da Fazenda, Ministério do Trabalho, Secretaria Estadual de Trânsito, escritório do Departamento Nacional de Estradas e Rodagens. Este lugar oferecia também infra-estrutura imobiliária capaz de absorver parte da demanda por residências, que aumentara com a chegada dos empreendedores.

Na época da construção, final da década de 1970 e início de 1980, as madrugadas de Abaetetuba foram marcadas pelo intenso movimento de ônibus e caminhões que transportavam os trabalhadores, peões, para os canteiros de obras da Albrás/Alunorte. Estes constituíam a força de trabalho migrante não especializada absorvida em maior quantidade nos momentos iniciais da implantação da estrutura física do projeto: desmatamento, construção de prédios do complexo de produção, porto, estradas e o núcleo urbano. De acordo com Fontes (1989) eram trabalhadores de Minas Gerais, Bahia, Maranhão, Piauí, Pernambuco, Ceará, e outros lugares do Brasil; muitos tinham participado da construção de projetos hidroelétricos como Tucuruí, Paulo Afonso, Sobradinho, Balbina. Estas experiências foram confrontadas com as dos trabalhadores da região que na sua grande maioria não tinham participado de qualquer experiência assalariada, muitas vezes presos à sua trajetória camponesa, com

\footnotetext{
${ }^{2}$ Entrevista nos concedida em Janeiro de 2004.
} 
NAHUM, J.S. Usos do território, modernização e ações políticas ...

expectativas em relação aos patrões, conduzidas por valores morais, como honra e lealdade.

\section{O uso do território pela Albrás/Alunorte}

Empresa produtora de alumínio primário, a Albrás possui, atualmente, a maior capacidade instalada do Brasil. Ela foi implantada, no final dos anos 70, resultado de um acordo binacional entre os governos do Brasil e do Japão. Ela tem como acionistas a Companhia Vale do Rio Doce (CVRD) com 51\% do capital, representada por sua subsidiária Vale do Rio Doce Alumínio - S/A ALUVALE- à época a CVRD não era totalmente privatizada, o que ocorreria em 1997; e a Nippon Amazon Aluminium Co. Ltda - NAAC, uma associação de 32 empresas japonesas, com $49 \%$ do capital. O investimento total para implantação da Albrás foi de US\$ 1,5 bilhão.

A área definida para a instalação do complexo industrial produtor de alumínio em Barcarena, localizado a $7 \mathrm{~km}$ da sede do município, ocupa $40.000 \mathrm{ha}$, distribuídos da seguinte forma (Mapa 1): a)- a área industrial: compreende o porto localizado em Ponta Grossa, na Vila do Conde; a área da Alunorte, próximo ao porto; a área da Albrás, situada em frente ao porto e contínua ao lote da Alunorte; a área da Eletronorte, situada próxima ao lote da Albrás destinada à instalação da subestação rebaixadora de tensão, que chega da hidrelétrica de Tucuruí; e a área de expansão, colocada à disposição da Companhia de Distritos Industriais do Pará - CDI, para a instalação do Distrito Industrial; b)- a área de expansão urbana: reservada a atender a demanda de lotes industriais; c)- $a$ área de transição: destinada à proteção da Reserva Ecológica e apoio das atividades diversificadas, de natureza industrial; d)- $a$ área de implantação do Novo Núcleo Urbano de Barcarena: onde estão instaladas as residências dos trabalhadores da Albrás/Alunorte. 
NAHUM, J.S. Usos do território, modernização e ações políticas ...

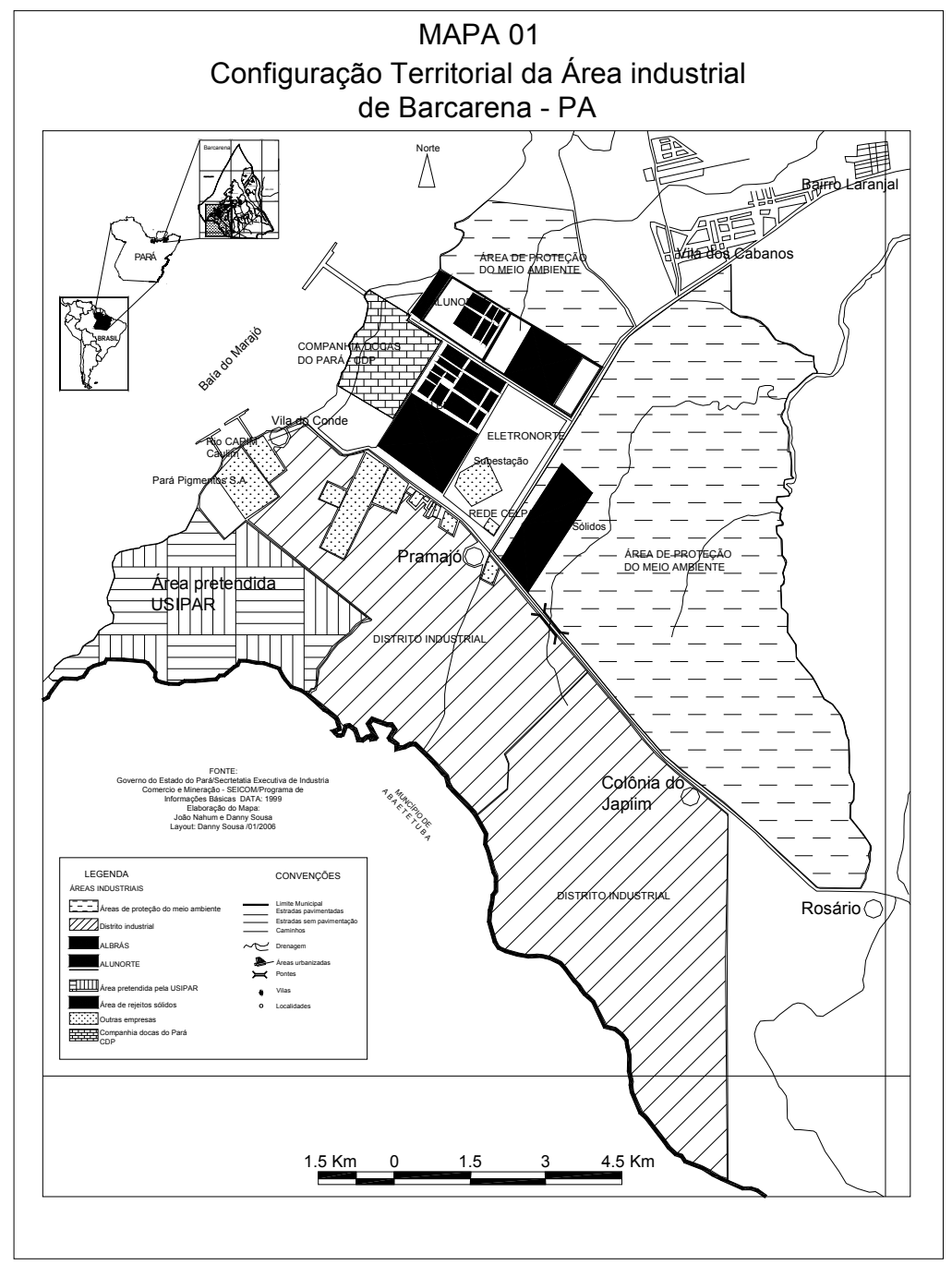


NAHUM, J.S. Usos do território, modernização e ações políticas ...

A escolha da área onde o complexo Albrás/Alunorte se localiza levou em consideração: 1)- a relativa proximidade das fontes de seus principais insumos - bauxita e energia elétrica; 2)- a possibilidade de construção e utilização de um porto que permitisse a atracação de navios de grande capacidade, acima de 40.000 toneladas; 3)- as características de solo com topografia plana e do subsolo bastante favorável para o suporte de fundações da fábrica; 4)- a existência de água com qualidade e volume para uso industrial; 5)- a disponibilidade de mão-de-obra barata; 6)área com baixa densidade de ocupação e, ao mesmo tempo, próxima de um grande centro urbano. Após análise dos fatores e diante das alternativas existentes, foi definido que ele deveria ficar na área de influência de Belém. Barcarena era o território que reunia muitas dessas características vantajosas.

A planta industrial, os sistemas de abastecimento de energia e matérias-primas, a rede de transporte, o porto, o núcleo urbano e as áreas de expansão, enfim todo esse sistema de objetos técnicos forma o que podemos com M. Santos (2005, p. 134) chamar de "um ponto ou mancha de meio técnico-científico-informacional". Esta parte da configuração territorial de Barcarena, de conteúdo marcadamente moderno, está associada ao tempo do mundo, "que é o tempo das empresas multinacionais e o das instituições supranacionais." (SANTOS, 1999, p.111). Enquanto para a maioria da população restam os mesmos e velhos problemas dado o uso desigual do território. Se de uma parte o território se moderniza como recurso para a riqueza de uns poucos, de outra parte a maioria sofre com a falta de investimentos sociais. Tudo isso concorre para acentuar os usos desiguais do território ao mesmo tempo em que se aprofunda a divisão entre as classes sociais.

\section{O uso do território pela elite governante local}

O complexo Albrás/Alunorte constitui um ponto ou mancha de meio técnico-científico-informacional no território, o que atraiu para aí empresas como Pará Pigmentos (caulim), Imery Rio Capim Caulim S/A (caulim), Alubar Metais S/A (fio de alumínio). Isso 
NAHUM, J.S. Usos do território, modernização e ações políticas ...

possibilitou a Barcarena integrar o seleto grupo de $6 \%$ dos municípios paraenses que têm seu PIB (Produto Interno Bruto) ${ }^{3}$ sustentado, predominantemente, na atividade industrial. Ali a atividade industrial participa com 78,12\% na composição do PIB, o setor de serviços com $20,91 \%$, e a agropecuária contribui com $0,97 \%$.

O montante do orçamento de Barcarena está umbilicalmente dependente da arrecadação e repasse de impostos provenientes da implantação de complexos industriais minero-metalúrgicos. Isso pode ser comprovado comparando-se o percentual de retorno do Imposto sobre Circulação de Mercadorias e Serviços (ICMS) ao município. No primeiro semestre de 1993 foi da ordem de 2,82, passando para 6,39 no primeiro semestre de 2006. O fato de ter uma fração do território comandada por essas empresas é compensado, por assim dizer, pelo crescimento da receita municipal através do aumento das transferências constitucionais, o que permite ao município dispor em 2002 da maior renda per capita do estado do Pará, $\mathrm{R} \$ 19.1032,69^{4}$.

No entanto, a elite governante usa a gestão dos recursos para a reprodução de sua hegemonia política e econômica. Na lógica dessas elite legislar e administrar são sinônimos de despachar, implementar políticas de assistência social em detrimento de políticas públicas. Entenda-se por despachar o atendimento pelo prefeito, na sua residência ou no seu gabinete, aos membros da administração direta e, especialmente, a população. No território de Barcarena, despacha-se "como se" a instituição pública municipal, com suas estruturas e recursos, fosse de domínio privado do gestor. A gestão pública assume conotação pessoal, "como se" o gestor estivesse administrando sua casa, unindo, como lembra Da Matta (2001), "a lei com a realidade social diária". Nesta prática política, tal como no patrimonialismo examinado por Faoro (1991), dissolve-se qualquer limite entre os interesses da instituição

\footnotetext{
${ }^{3}$ Disponível: $<$ http://www.sepof.pa.gov.br>Acesso em: 08.06.2005.

${ }^{4}$ Disponível: $<$ http://www.sepof.pa.gov.br/estatistica/PIB/Ranking/PIB_pe rcapita_precos_mercado.pdf $>$
} 
NAHUM, J.S. Usos do território, modernização e ações políticas ...

pública e os interesses particulares. Conseqüentemente, sem o reconhecimento desses limites o bem comum torna-se uma falácia, assim como o espaço público, a esfera pública, a gestão pública, e, portanto, a cidadania no território torna-se uma quimera.

Os mecanismos de controle e físcalização da gestão pública são silenciados, ou seja, funcionam de acordo com o sistema de ações conservadoras, conseqüentemente, os gestores comportam-se como proprietários do patrimônio público, utilizando os recursos municipais de acordo com as suas próprias conviç̧ões e interesses. A atividade política reduz-se ao gerenciamento de interesses individuais. Isso lhes permite, por exemplo, não priorizar a cobrança de tributos municipais, principalmente o Imposto Predial Territorial Urbano - IPTU, o que também constitui prática clientelista.

Em 2000 a receita do IPTU foi projetada em $\mathrm{R} \$ 876.370,00$ e sua arrecadação foi de R\$ 921.583,00. Em 2001 houve uma previsão de arrecadar $\mathrm{R} \$ 1.000 .000,00$, projetando-se uma inadimplência de $50 \%$ e $2 \%$ de isenções, arrecadou-se $\mathrm{R} \$$ $743.895,00$. A estimativa de arrecadação para o ano de 2002 foi somente $40 \%$ do previsto no ano anterior. Ainda que se saiba na elaboração da Lei de Diretrizes Orçamentárias para o exercício de 2002, a receita do IPTU havia alcançado quase o projetado para o exercício de $2000^{5}$.

Do mesmo modo, os instrumentos de planejamento administrativo, tais como, o Plano Plurianual são utilizados, tão somente, para mostrar onde e como seriam aplicadas as receitas municipais. Dentre as metas do programa "Saúde Para Todos" da secretaria municipal de saúde consta a implantação de 04 leitos de UTI no Hospital Municipal e a construção e aparelhamento de Unidade de Saúde com 30 leitos na sede do município. Para o período de 2002-2005 o primeiro projeto prevê alocar $\mathrm{R} \$$ $600.000,00$ e o segundo, $\mathrm{R} \$ 500.000,00$. A cidade, no entanto, até dezembro de 2004, dispunha de 81 leitos hospitalares, o mesmo número de leitos do ano de 1999; conta ainda com 18 unidades

\footnotetext{
${ }^{5}$ Fonte: Lei de Diretrizes Orçamentárias de Barcarena - 2001, 2002 e 2003.
} 
NAHUM, J.S. Usos do território, modernização e ações políticas ...

ambulatoriais cadastradas no SIASUS, número inferior ao ano de 1999, quando eram 21 unidades $^{6}$.

Algumas metas do Programa de Educação parecem as de um programa da secretaria de infra-estrutura:

a)- construção de Escola Técnica e Universidade, para o período de 2002-2005, com alocação de $\mathrm{R} \$ 246.000,00$;

b)- construção, implantação e manutenção de um Instituto de Nível Superior. Para o período de 2002-2005 este projeto tem alocado R \$ 340.350,00;

c)- construção e manutenção do prédio para o Conselho Municipal de Educação. Para o período de 2002-2005 este projeto tem alocado $\mathrm{R} \$ 50.000,00$;

d)- construção e manutenção do prédio próprio da Secretaria Municipal de Educação. Para o período de 2002-2005 tem alocado $\mathrm{R} \$ 395.820,00$.

Estas metas de "construção" da Secretaria de Educação não se realizaram. De acordo com dados do $\mathrm{IBGE}^{7}$ sobre o ensino, matrículas, docentes e rede escolar em Barcarena, até o ano de 2004 a rede pública municipal não contava nem com escola de ensino superior, nem docente e aluno; também não contava com escola técnica pública municipal e instituto de ensino superior, nem docente e aluno. Tão fabulosa quanto "as metas de construção" da escola técnica, da universidade e do instituto de ensino superior é a "construção e manutenção" do prédio do Conselho Municipal de Educação; este sequer existe na forma de lei municipal ${ }^{8}$, aliás, nem a Secretaria Municipal de Educação funciona em prédio próprio, ocupando o mesmo prédio da Câmara Legislativa.

\footnotetext{
${ }^{6}$ Disponível:<http://www.sepof.pa.gov.br/estatistica/ESTATISTICAS_M UNICIPAIS/Mesorr_Metrop_Belem/Belem/Barcarena.pdf $>$.Acesso em: 01 Dez. 2005.

${ }^{7}$ Disponível:<http://www.ibge.gov.br/cidadesat/xtras/temas.php?nomemu $\mathrm{n}=$ Barcarenacondmun=1501 $>$. Acesso em: 01. Dez.2005.

${ }^{8}$ Disponível: < http://www.ibge.gov.br/munic2001/index.htm> . Acesso em 22. jun. 2004.
} 
NAHUM, J.S. Usos do território, modernização e ações políticas ...

Em Barcarena, a gestão dos recursos também origina um projeto infindável de obras, o que faz parecer que as ações governamentais sejam uma política ativa. No entanto, o que esconde tal projeto de obras e ações políticas é o uso do território como recurso para manutenção de seu domínio político. Nunca há orçamento suficiente para terminar as obras e ela resta ali como propaganda das ações governamentais ou quando são terminadas são apresentadas como uma doação dos próprios governantes à sociedade. Há que se afirmar que o orçamento dessas obras é dinheiro público, portanto da própria sociedade e que não é presente deste prefeito ou daquele vereador.

Mas a inauguração é um ato solene, momento no qual o "benfeitor" se apropria da "obra", batizando-a e "presenteando" a sociedade barcarense. Lê-se no jornal Diário do Pará de 23 de abril de 2002:Os moradores de Barcarena receberam, ontem, um presente, durante a comemoração dos 46 anos do prefeito Laurival Magno Cunha (PMDB). Foi o início das obras de construção do cais de arrimo, que fará parte de um grande complexo turístico na orla local.

Assim é que também a elite governante municipal usa o território como recurso e reproduz um sistema de ações conservadoras, cuja lógica particularista reproduz em Barcarena práticas clientelistas, que vivificam a economia do voto e a política de alianças eleitorais entre as famílias; o mandonismo político, que ameaça com desemprego o funcionário público que não obedecer as ordens da gestão dominante e o patrimonialismo que dissolve os limites entre patrimônio público e interesse privado.

Um resultado dos usos e abusos do território pela ação empresarial e das elites locais é a formação, nos arredores da Albrás/Alunorte, de lugares de ocupação espontânea (MAPA 2), que não obedecem ao reordenamento territorial arquitetado pela lógica das empresas, mas testemunham o aumento das desigualdades territoriais. Nos momentos iniciais de formação destes lugares têm-se indefinição na jurisdição administrativa, pois nem as empresas nem a elite governante municipal se 
NAHUM, J.S. Usos do território, modernização e ações políticas ...

responsabilizam por urbanizá-los. A população, que aí reside precariamente, sem infra-estrutura alguma, fica a mercê das ações políticas tradicionais que se reproduzem contraditoriamente com o projeto de modernização da gestão pública.

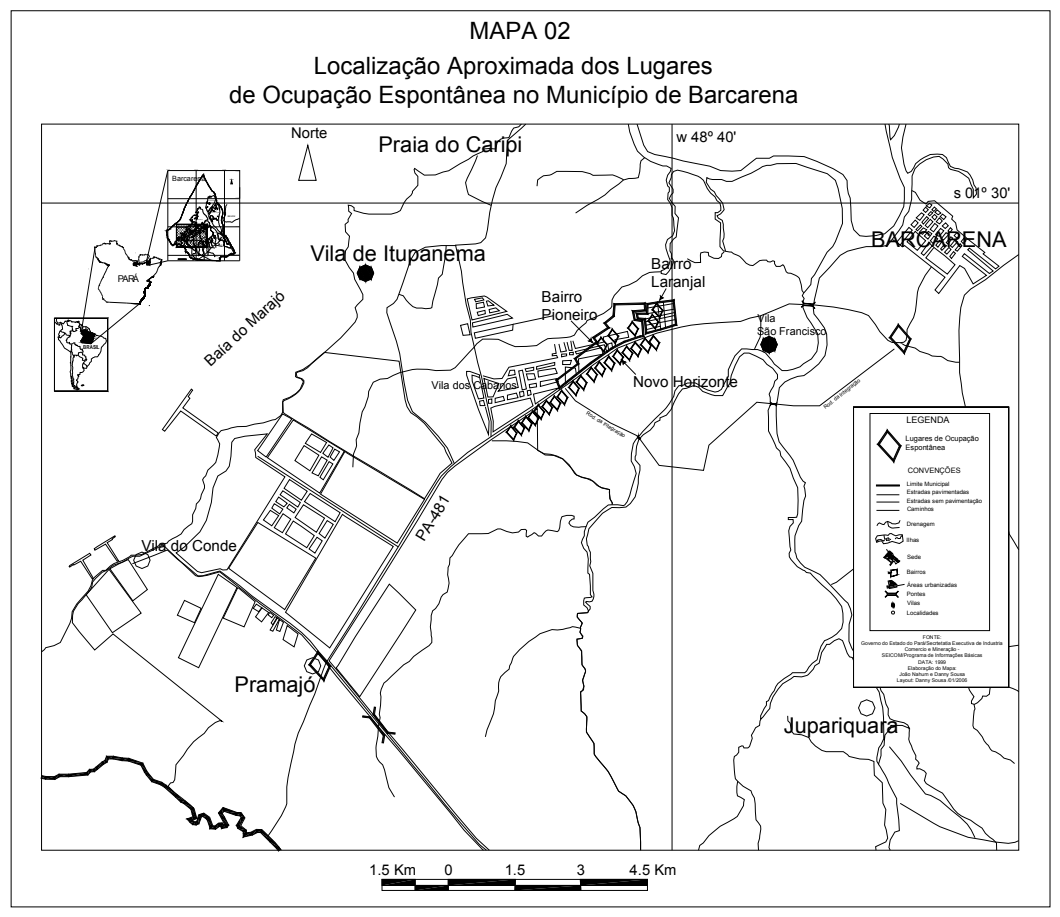

Os agentes hegemônicos da política têm essa parte do território municipal, onde a população pobre reside, como um recurso, um lugar privilegiado para difundir suas ações assistencialistas. Nos lugares de ocupação espontânea, como Bairro Novo, Novo Horizonte, Bairro Laranjal, além das áreas rurais e ribeirinhas das ilhas, a maioria da população aí residente enfrenta o desemprego, condições precárias de habitação e até alimentação. 
NAHUM, J.S. Usos do território, modernização e ações políticas ...

Podemos mesmo dizer que a manutenção da pobreza nesses lugares cumpre a função de garantir a continuidade da elite no poder, isto é, esses territórios justificam as políticas sociais e impedem a realização de políticas públicas. É um círculo vicioso. Assim, segundo Almeida (2004), "as chamadas 'políticas sociais' seriam 'focalizadas e não necessariamente públicas', consistindo tão somente num instrumento de funcionalização da pobreza" (ALMEIDA, 2004, p. 41).

No atendimento imediato dessas demandas, a gestão municipal transforma os órgãos de administração, mormente a secretaria de assistência social e a câmara de vereadores, em centrais de atendimento e suprimento de uma gama de solicitações. O "Programa Plantão Social", desenvolvido pela secretaria de ação social, realiza atendimentos emergenciais com concessões variadas, de acordo com a necessidade da demanda existente. Auxílio funeral, certidão de nascimento, encaminhamento de $2^{\mathrm{a}}$ via de carteira de identidade, ajuda de custo para famílias imigrantes, cestas básicas de alimentos, ofertas de medicamentos com prescrição médica dentre outros, bem como encaminhamentos diversos da população carente para entidades públicas e privadas.

Os lugares de ocupação espontânea testemunham as desigualdades territoriais produzidas a partir do novo que aí se instala com a chegada, por exemplo, de um grande empreendimento, a Albrás/Alunorte. Todo o processo de reordenamento territorial exigido para a implantação dessas empresas, tais como a construção de sistemas de produção, energia, transporte e comunicação, um núcleo urbano planejado, os lugares de ocupação espontânea e o crescimento das receitas do município, tudo integra uma modernização fabulosa feita de simulações e artifícios, mais preocupada em parecer moderna do que em ser moderna, posto que esconde o sistema de ações políticas conservadoras que usa o território como recurso para garantir os interesses do pequeno círculo dos agentes decididores, as empresas e a elite governante municipal. 
NAHUM, J.S. Usos do território, modernização e ações políticas ...

\section{Conclusão}

$\mathrm{Na}$ dinâmica territorial de Barcarena reproduz-se a modernização conservadora e que, segundo Becker e Egler (1994, p. 33) é a via latino-americana para a modernidade, onde o Estado negocia com grupos privilegiados a manutenção de privilégios e a sua inclusão ou exclusão na apropriação da coisa pública, em troca do apoio de modernização de cima para baixo.

A modernização tem sido um projeto que visa tão somente o uso mais eficaz do território para reprodução dos interesses da classe dominante, que ordena o território à luz da razão instrumental, apoiada na concepção de natureza sinônimo de recursos naturais, de espaço, freqüentemente, acompanhado do adjetivo "vazio" ou da expressão a ser "ocupado e/ou integrado" ao conjunto do espaço nacional e mundial. Essa ideologia da fronteira é outro nome para a modernização fabulosa, uma fábula patrocinada pelo Estado, que oferece um leque de vantagens aos empreendedores que usam o território nacional sem outra finalidade que aquelas privatísticas de seus interesses corporativos e a despeito da sociedade brasileira.

Essa dialética entre modernização e conservação vem se reproduzindo na dinâmica territorial brasileira e, portanto, também em Barcarena. Aqui, as modernizações, a partir da implantação da Albrás/Alunorte, favorecem o uso corporativo do território como recurso, tanto pela Companhia Vale do Rio Doce e da Nipon Aluminium Company, quanto pela elite governante local para fortalecer e conservar sua hegemonia política e econômica. Assim sendo, o sistema de ações conservadoras da elite governante de Barcarena é também responsável pela reprodução de um território desigual, dividido e heteronômico.

Esse tipo de ação tem aprofundado a dependência da população em relação às ações assistencialistas e às políticas de despachos, posto que moderniza, mas conservando a lógica de dominação do sistema; e conserva a lógica de dominação do sistema, usando dos processos de modernização. Em ambos, modernização significa então garantir os privilégios e a realização 
NAHUM, J.S. Usos do território, modernização e ações políticas ...

dos fins estabelecidos; consiste, principalmente, em usar o território de modo mais eficiente para realização das finalidades de poucos em detrimento da maioria.

\section{Referências bibliográficas}

ALMEIDA, Alfredo Wagner Berno de. Solidariedades Ameaçadas e a Redefinição do Serviço Público. In: NEVES, Rosa Helena Nascimento; QUINTELA, Rosângela da Silva; CRUZ, Sandra Helena Ribeiro (Orgs). A Reinvenção do Social. Poder Local e Política de Assistência Social em Belém (1997-2004). Belém: Editora Paka-tatu. 2004, pp.39-60.

BECKER, Bertha; EGLER, Cláudio A.G. Brasil. Uma Nova Potência Regional na Economia-Mundo. $2^{\mathrm{a}}$ Edição. Rio de Janeiro: Bertrand Brasil, 1994.

DA MATTA, Roberto. O Que Faz do Brasil, Brasil? Rio de Janeiro: Rocco, 2001.

FAORO, Raymundo. Os Donos do Poder. Formação do Patronato Político Brasileiro. 9a Edição. São Paulo: Editora Globo, 1991.

FONTES, Edilza. O peão de trecho e o peão de casa: a identidade operária entre os trabalhadores da construção civil de Barcarena no canteiro de obras da ALBRAS/ALUNORTE. In. MAGALHAES, Sonia Barbosa; BRITTO, Rosyan de Caldas; COSTA, Edna Ramos de (Orgs) Energia na Amazônia. Vol 1. Belém: MPEG/UFPA, 1996.

IANNI, Octávio. A Ditadura do Grande Capital. Rio de Janeiro: Civilização Brasileira, 1981.

LOBO, Marco Aurélio Arbage. Estado e Capital Transnacional na Amazônia: o caso da Albrás-Alunorte. Belém: UFPA/NAEA, 1996. 
NAHUM, J.S. Usos do território, modernização e ações políticas ...

MAIA, Maria Lúcia Sá; MOURA, Edila A. Ferreira. Da Farinha ao Alumínio: os caminhos da modernização na Amazônia. In: CASTRO, Edna; MOURA, Edila A.Ferreira; MAIA Maria Lúcia Sá. (Orgs). Industrialização e Grandes Projetos. Desorganização e Reorganização do Espaço. Belém. Editora Universitária. UFPA. 1995, pp. 223-260.

OLIVEIRA, Francisco de. Os Direitos do Antivalor. A economia política da hegemonia imperfeita. Petrópolis(RJ): Editora Vozes, 1998.

SANTOS, Milton. Da Totalidade ao Lugar. São Paulo: Edusp, 2005.

A Natureza do Espaço. Técnica e Tempo. Razão e

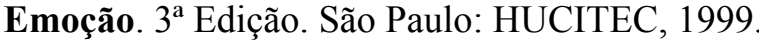

VASCONCELOS, Ana Maria de Albuquerque. Transformações Sociais e Lutas Cotidianas no Laranjal em Barcarena. Relatório Final de Pesquisa. Belém. UNAMA, 1996

Recebido em novembro de 2006 Aceito em julho de 2007 